\title{
Mudando o coração, a mente e as calças. A Arqueologia Sensorial
}

\author{
José Roberto Pellini *
}

PELLINI, J.R. Mudando o coração, a mente e as calças. A Arqueologia Sensorial. Revista do Museu de Arqueologia e Etnologia, São Paulo, 20: 3-16, 2010.

Resumo: Como tem apontado Classen $(1993,1997)$ e Howes $(1991,2006)$, estudos etnográficos, históricos e antropológicos têm demonstrado que a percepção sensorial é uma construção cultural, ou seja, os significados que os individuos atribuem para os aspectos sensoriais são baseados nos modelos sensoriais adotados socialmente. Sendo assim, cada cultura concebe os sentidos de maneira diferenciada estabelecendo suas próprias hierarquias sensoriais (Howes 2006). Neste sentido, o entendimento sensorial do mundo não é apenas um aspecto fisiológico, mas é culturalmente determinado. Os grupos humanos reconhecem o aparato sensorial de acordo com seu próprio contexto, criando e mudando sentidos, criando e alterando hierarquias sensoriais. Nós aprendemos a ver, ouvir, sentir. Nós aprendemos a observar e não observar. Neste sentido a Arqueologia Sensorial busca entender a experiência humana a partir da compreensão de como se dá a relação entre os indivíduos e o mundo material, partindo do pressuposto de que da mesma maneira que os objetos suscitam sensibilidades eles são sensiveis aos modelos senso-culturais de um grupo.

Palavras-chave: Arqueologia Sensorial - Percepção - Fenomenologia Materialidade.

Percepção é a filosofia do dia a dia, a ordem não falada pela qual nós vivemos e sustentamos todos os nossos atos, palavras e pensamentos. Merleau-Ponty (1962)

\section{Mais um devaneio}

T $m$ dia destes, caminhando às margens do Araguaia enquanto fazia uma prospecção, me pus a pensar sobre a complexi-

(*) GRIPHUS Consultoria. <jrpellini@yahoo.com.br> dade de nossas vidas; sobre a infinidade de situações, caminhos e decisões que enfrentamos no dia a dia e como isso afeta nossa relação com o mundo e com os objetos. Se mal conseguimos identificar os símbolos que nos rodeiam quotidianamente, como podemos ansiar entender os do passado? Por exemplo, você ai sentado, tire por um minuto apenas os 
Mudando o coração, a mente e as calças. A Arqueologia Sensorial. Revista do Museu de Arqueologia e Etnologia, São Paulo, 20: 3-16, 2010.

olhos destas linhas e dê uma olhada na disposição dos objetos ao seu redor. O computador ligado, os livros espalhados, algumas coleções de material arqueológico dispostos na mesa, outro tanto entulhado no canto da sala, cadeiras, mesas, canetas, números de telefone anotados em um pedaço de papel, cadernos rabiscados da sua última conversa telefônica, uma infinidade de fragmentos de cultura material dispostos de maneira tão corriqueira e desinteressada que você nem se dá conta da existência de muitos deles no dia a dia. Imagine aquele clipe que você já utilizou para tirar grampos de uma carta. Lembra daquela borracha que você usa para segurar o material arqueológico na hora da foto? E a caneta bic que você já utilizou para tantas outras coisas, menos para escrever, lembra dela? Você é capaz de dizer com segurança para que utilizou cada um dos objetos na sua sala? O que dizer então daqueles objetos há muito perdidos para você? Objetos no fundo da gaveta que por terem saido de circulação há tanto tempo mais parecem cacos cerâmicos enterrados em um sítio arqueológico. Cada objeto foi e será utilizado e descartado por algum motivo específico sujeito a inúmeras variáveis. Será que alguém entrando em sua sala poderia dizer algo sobre você, sobre suas inquietações, sobre seus sonhos e frustrações? Será que se alguém encontrar aquela chave no fundo da gaveta e analisar seu contexto e sua constituição será capaz de evocar uma memória, um passado pessoal, um ato distante? Será que você mesmo se dá conta dos usos e re-usos de todos os fragmentos de cultura material que estão dispostos em sua sala? Será que consegue retratar, descrever ou simplesmente lembrar com detalhes as impressões que teve na reunião de ontem em sua sala com aquele estagiário chato?

Basta pensarmos em nosso cotidiano para concluirmos que nossa relação com os objetos é complexa e cheia de variantes. Neste sentido creio que a reconstrução dos usos e re-usos da cultura material é bastante difícil.

Enquanto continuava andando ouvi ao longe um barulho. Em meio às areias brancas surgiu um senhor esguio, barba esbranquiçada, pés descalços. Sua voz é forte. Ele caminha na minha direção e diz: " .....Você me pede, Homem, que fale de mim mesmo, dentro da História e estórias que escreverá.......vou lhe atender Homem, porque você me chamou com dois braços de abraçar: o Amor e a Poesia. Mas lhe direi poucas das coisas que fascinam os seus irmãos porque as águas de todos os rios vieram de tão longe e nelas as coisas aconteceram há tanto tempo que suas lembranças foram guardadas para ninguém. Outros muitos homens por mim passaram mas nada me perguntaram, tão cegos que estavam por miragens além de meus barrancos que nem sequer me enxergavam. A nenhum deles falei ou falarei, mas conversei com você, Homem, e com quem para pra me olhar, quem para pra escutar os acordes regidos pelos ventos, para sentir o perfume sutil das sombras e por elas caminhar em cuidados de vigilia, para quem pisa livremente em minhas praias juntando as marcas de seus pés às pegadas de animais e riscos de aves ribeirinhas e sobre eles dormir sob a noite de mistérios......." (Borges 1986: 24).

Acordo sobressaltado. Parece que tive um desmaio. Mas quem era aquele homem? Teria sido apenas um sonho motivado pelo cansaço e pelas minhas inquietudes? Não sei, sei apenas que nasceu um desejo de mudança. De mudar nossa prática já tão mecanizada, de mudar nossa relação com os objetos, de mudar nossa relação com o passado.

Reconstruir a história das ocupações humanas não é apenas descrever e sintetizar um conhecimento físico expresso por um sítio arqueológico ou por um perfil estratigráfico, mas é, sobretudo, tentar captar as imagens que se formaram na retina daqueles que por algum motivo por ali passaram e ali se estabeleceram. Falar da ocupação humana é tentar compreender como as paisagens e objetos se formaram no coração e na mente de cada um dos povos do passado, não de um modo distanciado como propõe o paradigma científico dos séculos XIX e XX, mas de uma forma simbiótica, onde a natureza não é alheia ou externa ao homem.

Vivemos hoje um teatro de falas decoradas, de discurso pronto, onde sondagens se misturam com perfis estratigráficos, padrões de sedimentação se confundem com sistemas de 
descarte, arbustos se confundem com paisagens. A própria ciência se tornou nossa prisão e a desculpa conveniente para não avançarmos em nossas divagações. A racionalidade e a pretensa objetividade cientifica nos impedem de voar. Mas o que seria de Ícaro se pensasse apenas racionalmente? Precisamos tentar resgatar sentimentos, percepções e paisagens a fim de desenvolver uma arqueologia mais reflexiva tanto do ponto de vista teórico quanto metodológico. Sinta-se convidado a atravessar o espelho. Esta será uma viagem rumo ao desconhecido. Vamos tomar um chá com o chapeleiro, vamos lutar ao lado de Pan. Vamos abrir a caixa de Pandora e enfrentar nossos medos. Vamos sonhar. A promessa é de muitas aventuras.

\section{A percepção é a filosofia do dia a dia}

Caro leitor, paremos um momento esta leitura. Olhe novamente sua sala. Os livros dispostos na estante, as paredes em ângulo reto, a coloração branca e ocre do ambiente, a cadeira reconfortante no centro, o tapete no qual você tropeça todos os dias, a mesa sempre bagunçada na qual você perdeu o artigo que era para enviar para a editora, a coleção de discos da Disney empoeirados e o boneco do Johnny Deep vestido de Chapeleiro Louco, ao lado do computador; ops! Agora me responda para que serve esta sala? Alguns diriam que serve para estudar, imergir na ciência arqueológica. Outros diriam que serve para brincar de playmobil, outros ainda diriam que serve para tirar uma soneca e fugir da esposa na hora de lavar a louça do jantar. Então me pergunto por que, mesmo sabendo que objetos, construções, monumentos são criados para serem experimentados, utilizados, sentidos, os aspectos da experiência, da vivência são deixados de lado quando analisamos um sítio arqueológico ou uma coleção de objetos arqueológicos? Pergunto-me, monumentos, casas, construções eram criadas para serem experimentadas ou descritas? Artefatos eram feitos para serem manuseados ou para serem medidos e tabulados? Por mais que pareça óbvia esta constatação, porque então continuamos a apenas descrever nossos objetos de pesquisa? Talvez porque como arqueólogos tenhamos nos acostumado a registrar e interpretar sítios e artefatos de modo muito visual, afinal, nós desenhamos perfis, tiramos fotos, lemos e escrevemos relatórios, realizamos descrições detalhadas de objetos e sítios. Creio que o problema esteja no fato de que nossos hábitos como pesquisadores ainda estão demasiadamente enraizados nos paradigmas que sustentam a observação e a descrição como métodos objetivos e cientificos. Dubord (1995) descreve a emergência do novo mundo da razão como um espetáculo em que a experiência foi substituida pela observação. Mas será que a observação pode substituir a vivência na formação do nosso conhecimento?

Imaginemos por exemplo que você está caminhando durante uma prospeção arqueológica e ao longe avista um aglomerado de cacos cerâmicos no chão mas não consegue divisar exatamente do que se trata. Você se aproxima e observa o conjunto até que sua atenção é direcionada para um objeto especifico. Nossa uma ponta de flecha!!!. Neste momento este objeto se torna seu estimulo de atenção. Quando você repara na ponta de flecha e seu entorno imediado, uma imagem bidimensional se forma em sua retina. Na sequência esta imagem é transformada em sinais elétricos que são levados ao tálamo e projetados simultaneamente no córtex, rota perceptiva e nas regiões sub-corticais, rota emocional. Se o mecanismo de avaliação emocional reage ao estímulo, um sinal é enviado às áreas sub-corticais que regulam os estados do corpo. Simultaneamente as informações sensoriais são analisadas no córtex e o output pode ser projetado para os mecanismos de avaliação emocional que respondem se a emoção inicial é relevante ou não. Dentro deste processo, a conscientização de ver a ponta de flecha é chamada pela neurociência de percepção. Ela ocorre quando os sinais elétricos que representam a imagem bidimensional da ponta de flecha são transformados por nosso cérebro em uma experiência de ver a ponta de flecha. Percepção seria a forma como através dos sentidos as coisas do mundo natural e humano chegam a nossa consciência (Chauí 2000). 
Mudando o coração, a mente e as calças. A Arqueologia Sensorial. Revista do Museu de Arqueologia e Etnologia, São Paulo, 20: 3-16, 2010.

Segundo Nóbrega (2008), para compreendermos a percepção, e, por conseguinte nossa relação com o mundo, primeiro temos de entender o que é sensação. Para Reid (1970) devemos estabelecer uma diferença entre sensação e percepção. Para o autor sensação é o processo de sentir nosso mundo através do aparato sensorial, já a percepção é o meio pelo qual interpretamos as sensações. Merleau-Ponty (1962) foi um dos primeiros a criticar esta idéia. Para o autor não devemos pensar a percepção como sendo construída a partir de segmentos separados de dados sensoriais. Em vez de serem componentes elementares da experiência perceptiva, as sensações são construções teóricas. Isto se dá porque percebemos o mundo dentro de uma gestalt, ou seja tem forma e unidade. Além disso, esquecemos que o objeto percebido está sempre contextualizado, não apenas pelo seu ambiente físico, mas pelos interesses particulares de quem percebe, pelas ações especificas e ações potenciais em que o observador está envolvido e pelas especificidades culturais e históricas envolvendo o observador e outros aspectos da experiência que são constituídos de diferentes modalidades dos sentidos e das emoções. Para Chaui (2000) não existe diferença entre percepção e sensação. Ambas são a mesma coisa. Sensações não são propriedades intrínsecas dos objetos sentidos, mas propriedades da atividade neurológica que é causada por estímulos físicos que afetam nossos sentidos. Enquanto nossa informação sensorial é aproximada, nossa percepção é mutável. A mudança ocorre porque mudamos os conceitos que tomam parte de nossa percepção quando, por exemplo, vemos figuras ambiguas. Se sempre observássemos os objetos como eles são seria impossivel explicar a mudança entre duas diferentes percepções, desde que os objetos não mudam, mas nossa percepção sim.

Outro aspecto a se considerar é que vemos mais e menos do que aquilo que é dado sensorialmente, já que os objetos nunca nos são dados em sua totalidade. Voltemos à nossa ponta de flecha. Quando estávamos caminhando e deparamos com ela em nossa prospecção, ela estava enterrada, não estava? Você conseguia ver o objeto inteiro, inclusive a parte posterior que tocava o solo? Era possivel ver cada um dos detalhes da textura e da coloração da porção enterrada? Era possivel ver o gume sob as folhas secas? Creio que não. Mas pare e pense. Quando você deparou com a ponta concebeu apenas a porção visivel ou a ponta como um todo? Siiiim, pode responder, a ponta como um todo; mesmo não tendo completo acesso sensorial à ponta, "Eu" concebi a ponta de flecha em sua totalidade. Segundo Husserl (1962) isso se dá porque nossa percepção nos fornece uma completa consciência do objeto, mesmo que apenas parte do objeto percebido seja dado. O motivo para isto acontecer está enraizado no que Hurssel chama de intencionalidade horizonal, ou seja, a consciência do perfil atual do objeto é sempre acompanhado por uma consciência intencional do horizonte do objeto no que se refere aos perfis ausentes (Husserl 1970). Nossa consciência transcende o perfil perspectivo da ponta de flecha a fim de apreendê-la. A percepção assim nos fornece um objeto-consciência completo mesmo que somente parte do objeto seja intuitivamente dado. Ao mesmo tempo, lhe pergunto, você conseguiu ver todo o espectro eletromagnético refletido pela ponta de flecha? Ao tocá-la com sua marshalltown você escutou todas as ondas sonoras criadas? Também creio que não, afinal só vemos uma pequena faixa do espectro eletromagnético que chamamos de luz, assim como o ouvido humano só reage a estímulos entre 20 e 200 hertz. Está vendo como as aulas de física do colégio estão servindo para alguma coisa? Ao mesmo tempo às vezes vemos menos do que pensamos ver. Como demonstrou Dennett (1991), nós somos incapazes de distinguir cores na periferia de nosso campo visual. Somente quando um objeto se aproxima de nosso campo focal é que conseguimos perceber as cores. Neste sentido, podemos dizer que a percepção não é o conhecimento exaustivo e total do objeto, mas uma interpretação sempre provisória e incompleta que se dá a partir de perfis. Segundo Gallagher e Zahavi (2008), os tensionamentos dos perfis ausentes não se dão apenas com a visão, mas se estende aos demais sentidos.

Quando Husserl (1970) considerava o ato intencional consciente frente ao objeto fazia uma distinção entre intenção simbólica, intensão imaginativa e intenção perceptiva. Para ele não só estas formas de intenção não eram indenpendentes como eram hierarquizadas de 
acordo com sua capacidade de nos oferecer o objeto de maneira mais direta. Hurssel acreditava que a intenção simbólica era a mais afastada do objeto original, pois o ato simbólico embora seja assentado em uma referência, nos oferece o objeto de maneira indireta a partir de suas representações linguísticas. Já os atos imaginários, embora tenham um conteúdo mais intuitivo, também nos trazem os objetos de modo indireto através da imagem. Desta maneira, enquanto os atos simbólicos nos apresentam nossa ponta de flecha através de um signo linguístico, os atos imaginários nos oferecem a ponta de flecha através de uma representação em forma de imagem. A percepção é a única das intenções que nos oferece a ponta de flecha diretamente, ou seja, a percepção não nos confronta com signos, fotos ou imagens da ponta, mas nos confronta com ela mesma. Falar da ponta de flecha, ver a imagem da ponta e manusear a ponta, não é segundo Hurssel lidar com três pontas de flecha diferentes, mas com três maneiras diferentes de nos relacionarmos intencionalmente com ela, cada uma mais ou menos distante do objeto original. Para Husserl o ponto central da relação sujeito/ objeto é a consciência. A consciência é sempre consciência de algo que se manifesta a uma consciência. É nesta relação que Husserl identifica a base da realidade. Neste sentido o importante é a vivência, ou como define o autor, o processo pelo qual tudo que é informado pelos sentidos é mudado em uma experiência de consciência, em um fenômeno que consiste em estar consciente de algo (Cobra 2005). A fenomenologia de Husserl busca revelar o mundo a partir da experiência e não a partir do que acreditamos que a experiência seja. O mundo real é o mundo percebido, é o mundo vivido.

Percepção não é uma recepção passiva de informações e aqui está o ponto chave: percepção envolve movimento. O que vemos, sentimos é formado e determinado pelo que fazemos e o que somos capazes de fazer. É por isso que temos dificuldade de imaginar ou descrever situações que requerem movimentos que não são habituais para nós (Kaschak e Glenberg 2000). Nossos órgãos sensoriais funcionam conjuntamente com nossa experiência sinestésica. Para Husserl (1962), a percepção não é independente da dimensão sinestésica, elas trabalham juntas para formar um significado completo para o objeto da percepção. Se imaginarmos que estamos diante de nosso perfil estratigráfico, a ideia do perfil está completa e formada, mesmo que alguns perfis estejam ausentes. Os perfis ausentes estão ligados para um "se" intencional. Se eu me mover para a direita, se eu me mover para a esquerda, o novo perfil se torna acessivel. Neste sentido percepção pressupõe movimento e para entender a percepção precisamos entender a própria intencionalidade de nosso corpo. É por isso que Husserl dava ao corpo estatuto zero de referência no processo perceptivo, pois a percepção depende das habilidades sensomotoras do observador (Husserl 1970). Percepção não é algo que acontece em nós ou para nós, mas algo que nós fazemos (Noe 2004). Desta maneira o que percebemos é assim determinado também pelo que fazemos, pelo que somos capazes de fazer ou pelo que estamos prontos para fazer.

Neste momento, meu amigo Leandro pode estar pensando, enquanto caminha para aliviar a dor na lombar, sim, ótimo, está tudo lindo, maravilhoso, o texto está muito engraçadinho, mas como encaramos os estímulos perceptivos, a física e a química envolvida na recepção dos sinais sensoriais, aquele monte de neurônios e neurotransmissores, aquelas vias com nomes estranhos, os impulsos elétricos, os sistemas neurais? Hummm; difícil; hora de ascender um cigarro e correr. Brincadeira, vamos lá.

Segundo Nóbrega (2008), a neurociência tradicional considera que o sistema sensorial é formado por fibras aferentes que conduzem o estímulo da periferia para o sistema nervoso central e fibras eferentes que se encarregam de processar as informações e efetuar uma resposta. De acordo com Jarvilehto (1999), é com a ajuda dos receptores eferentes que cada organismo cria seu próprio mundo, simultaneamente objetivo e subjetivo. $\mathrm{O}$ autor argumenta que as células receptoras não têm como função exclusiva a conexão com o sistema nervoso central através das fibras aferentes já que se 
Mudando o coração, a mente e as calças. A Arqueologia Sensorial. Revista do Museu de Arqueologia e Etnologia, São Paulo, 20: 3-16, 2010

descobriu recentemente que elas também se inter-relacionam com as fibras eferentes. As conexões podem ocorrer de fora para dentro ou no interior do próprio organismo, por meio de sinais elétricos e químicos. As conexões eferentes influenciam os órgãos sensoriais na medida em que modificam a maneira como o organismo interpreta os estímulos do ambiente. Isso significa que a percepção não é um processo linear de decodificação de estímulos e sim, um círculo que envolve o sensório e o motor não como partes integrantes, mas como uma unidade dinâmica (Jarvilehto 1999). Neste sentido, embora o estimulo exista como estimulo ele assume configurações variadas para cada acontecimento. Segundo Nóbrega (2008), a percepção não apenas decodifica estímulos linearmente, mas reflete a estrutura do nosso corpo frente ao entorno, em contextos sociais, culturais e afetivos múltiplos. Segundo Maturana e Varela (1995), os movimentos, provocam modificações no estado do sistema aferente que, por sua vez, criam novos movimentos. Para Nóbrega (2000) na concepção tradicional, o movimento é causado por estimulos vindos do meio ambiente, dentro do esquema estímuloresposta. Os órgãos dos sentidos e suas fibras aferentes conduziam o estimulo e o sistema motor, com suas fibras eferentes, processava e executava a resposta. Na perspectiva da autopoiésis de Maturana e Varela (1995), a relação entre os sistemas aferente e eferente é modificada, sendo considerada circular e não mais linear. Sendo assim, Nóbrega (2008) afirma que a percepção emerge da motricidade onde o sistema nervoso central tem por função a condução do impulso e não a elaboração do pensamento. Ainda segundo a autora o que desencadeia certa resposta reflexa, não é um agente físicoquímico, é certa forma de excitação da qual o agente físico-químico é a ocasião antes que a causa. Quando nos movimentamos, há uma circularidade entre os acontecimentos do meio ambiente e os acontecimentos no próprio corpo, ocorrendo uma nova interpretação desses acontecimentos.

O tempo da percepção é o instante, ou seja, existe no momento em que recebemos a imagem, a partir deste momento já é tempo passado. A percepção vem e escapa a nossa mente criando outra imagem, tornando-se memória. Nesse sentido para Bergson (1990), quanto mais imediata a percepção mais real ela se torna, quanto mais distinto de nosso corpo por um intervalo, nunca exprime mais que uma ação virtual. Dentro deste universo, a percepção e as imagens que entram em nosso corpo são selecionadas pelo cérebro, ou seja, toda a percepção passa necessariamente pela nossa escolha. Este processo constitui para Bergson algo inexplicável, "o que você tem a explicar, portanto, não é como a percepção nasce, mas como ela se limita, já que ela em seu direito seria a imagem do todo, mas ela de fato se reduz àquilo que interessa a você" (Bergson 1990: 28. Tradução nossa).

No fim, não é a materialidade existir ou não, ou como ela existe no mundo o que importa, mas a maneira pela qual o conhecimento acontece, o ato pelo qual a pessoa apreende imediatamente o conhecimento de alguma coisa. Segundo Kant, nós não podemos conhecer inteiramente as coisas porque nem todos os sinais que recebemos das coisas são aceitos pela mente, assim não podemos conhecer inteiramente o real. Conhecemos o real apenas naquilo que a mente pode assimilar, sendo assim conhecemos o perfil estratigráfico porque na realidade o reconhecemos enquanto informação.

Como temos visto não podemos acreditar cegamente naquilo que o mundo nos oferece, pois no mundo, as essências estão acrescidas de acidentes enganosos, por isso, é preciso fazer variar imaginariamente os pontos de vista sobre a essência para fazer aparecer o invariante. Acredito não exista algo como uma face objetiva pura da realidade. No mundo da objetividade pura, o homem está ausente. É um mundo árido, só de conceitos. Mas ao mesmo tempo não acredito em uma subjetividade que crie ou se imponha absolutamente ao mundo. O que efetivamente existe são os múltiplos aspectos da interação dessas duas dimensões.

Merleau-Ponty (1962) acreditava, ao mesmo tempo, que a percepção não é apenas individual, ela tem um caráter social, isto porque não vivemos sós no mundo. Desta maneira, nossa 
ponta de flecha está sempre lá para os outros também, mesmo que esses atores não estejam em cena. Segundo Chaui (2000) e Jacobs (2006), nossas experiências culturais influenciam diretamente nossa percepção do mundo na medida em que percebemos os objetos no mundo não como eles são, mas percebemos através da mediação entre conceitos préexistentes originários de nossas experiências culturais. Sendo assim cada imagem do mundo é composta de estímulos que são processados através da experiência pessoal, aprendizado, imaginação, memória etc..

Em resumo, a experiência perceptiva não é determinada apenas pelos estados neuronais, ela depende das habilidades sensório-motoras do observador, das possibilidades oferecidas pelo ambiente e dos condicionamentos da cultura. Entender o processo perceptivo é importante na medida em que um individuo organiza e interpreta as suas impressões sensoriais para atribuir significado ao seu meio, ou seja, o comportamento das pessoas é baseado na interpretação que fazem da realidade e não na realidade em si. Pela percepção formam-se imagens que têm significados diferentes para quem as capta, dependendo de sua cultura, tempo histórico, situação psicológica, emocional etc..

\section{O império dos sentidos}

Embora no Ocidente estejamos acostumados a pensar nos sentidos apenas como uma resposta fisiológica dos órgãos sensoriais aos estimulos emitidos pelo mundo externo, os sentidos são algo mais. Eles são habilidades que empregamos diariamente na interpretação e avaliação do mundo, na mediação entre os significados e materialidades de nosso entorno. Para ver, por exemplo, precisamos mais do que abrir os olhos para permitir que a luz seja captada por nossa retina. Para ver, precisamos perceber o que é visto e, assim, dar sentido à experiência somática (Rodaway 1994). Classen (1993, 1997) e Howes (1991) defendem que percepção é uma construção social, ou seja, os significados que os individuos atribuem para os sentidos são baseados nos modelos adotados e aceitos socialmente. Cada cultura desta maneira concebe os sentidos de modo diferenciado, estabelecendo seus próprios modelos e hierarquias sensoriais (Howes 2006). Desta maneira, o entendimento sensorial do mundo não seria apenas um aspecto fisiológico, mas seria culturalmente determinado. Grupos humanos reconhecem seu aparato sensorial de acordo com o contexto cultural no qual estão inseridos, criando e mudando sentidos, criando e alterando hierarquias sensoriais (Howes 2006 a). Segundo Crary (1990), definidos em termos de capacidades sensoriais, potencialidades meio ambientais e significados culturais, os modelos sensoriais adotados por uma sociedade assumem conceitos locais que acabam sendo definidos pela tradição e pela prática. Nós aprendemos a ver, ouvir, sentir. Nós aprendemos a observar e não observar.

Classen (1993) demonstrou que a maioria das culturas apresenta um balanço sensorial próprio. Enquanto alguns grupos tendem para uma igualdade entre os sentidos, outros manifestam a primazia de um sentido particular ou de um grupo de sentidos. Ao mesmo, tempo nem todas as sociedades apresentam a mesma divisão aristotélica dos sentidos que o Ocidente. Por exemplo, enquanto os javaneses dividem seus sentidos em visão, audição, olfato, sentimento e fala (Dundes 1981), os Hausa dividem os sensos em apenas dois, a visão e o ji, que representa todos os demais sentidos (Ritchie 1991). Já os Cashinahua do Peru classificam os sensos em pele, mão, ouvido, genitália, figado e olhos. Segundo Kensinger (1995), os Cashinahua atribuem o conhecimento do mundo ao conhecimento da pele, pois é através da pele que sentimos o calor do sol, a chuva, o vento, a floresta etc., por outro lado, o conhecimento social advém dos ouvidos, do ato de escutar os outros individuos do grupo.

Diferenças nos modelos sensoriais resultam em diferentes formas de interpretar o mundo. É por isso que no mundo ocidental mapeamos o meio através da visão e os Kaluli de Papua Nova Guiné mapeiam sua paisagem através dos sons (van Ede 2009). Já entre os Desana da Colômbia, o mundo existe essencialmente 
Mudando o coração, a mente e as calças. A Arqueologia Sensorial. Revista do Museu de Arqueologia e Etnologia, São Paulo, 20: 3-16, 2010.

através das cores, isto porque segundo eles todos os seres vivos possuem seu próprio campo de cores. As cores representam para os Desana também a idade, o status, o conhecimento e o estado emocional dos individuos.

Entre os Ewe de Gana, o movimento é o senso mais relevante, desde que como uma pessoa se move indica seu conhecimento do meio, sua idade e seu status social dentro da comunidade (Geurts 2002). Entre os Suya, quando um caçador recorre ao shamam para que lhe ajude a caçar melhor, não é sobre a visão que o shamam atua e sim sobre o braço, pois para os Suyas, é a precisão tátil que determina um bom caçador e não a visão (Seeger 1975).

Entre os Dongon de Mali, as palavras além de sua natureza invisivel têm uma propriedade material maior que o som, ela tem odor, pois para eles sons e cheiros têm vibração e origem comuns. De acordo com as concepções Dogons, palavras podem ser classificadas pelo cheiro. Assim palavras boas têm cheiro adocicado enquanto palavras ruins têm cheiro forte. Ao mesmo tempo palavras ruins e impetuosas estão associadas à flatulência.

Os Ongee das Ilhas Andamon no Pacifico ordenam o mundo pelo olfato. Para eles o odor representa a força vital do universo sendo a base da identidade social. Já para os Tzotil do México é o calor que representa a força primária. Neste caso, a ordem social é determinada pelo sensorial térmico, ou seja, quanto mais importante dentro da hierarquia social mais próximo se está do sol por exemplo.

Se no Ocidente a estética é primariamente visual, sendo a beleza apenas aparência, entre os Shipibo do Peru, as experiências estéticas envolvem o olfato, a audição e a visão conjuntamente (Gebhart-Sayer 1985). Entre os Navajos, a experiência estética está associada aos aspectos táteis como se vê no ritual da pintura da areia (Classen 1993). Segundo a autora, enquanto os ocidentais vêm a pintura como objetos visuais, os Navajos pensam e atuam na dimensão tátil da pintura. Lembremos que na arte ocidental, é a contemplação que é estimulada, sendo que a própria técnica da perspectiva busca desligar os demais sentidos em benefício da visão. Ellen
Basso (1985) em seu livro, A Musical View of the Universe, relata que para os Kalapalos seus copos de cristal não eram vistos e não adquiriam significados por sua função visual, mas sim pelo som que eles emitiam quando tocados.

As hierarquias sensoriais não são estáticas, elas mudam com as estações com os anos, com a idade. No Ocidente, por exemplo, Origen, teólogo do século III, sugeria a existência de sentidos espirituais que permitiam a transcendência dos fenômenos (Classen 1993). Segundo a proposição de Origen, os sentidos espirituais da memória, instinto, imaginário, fantasia e senso comum se correlacionavam diretamente aos sentidos aristotélicos. Maloney (1976) demonstrou como nem sempre a visão foi o sentido mais importante no Ocidente. Segundo o autor na Europa Medieval, era muito difundida a crença na visão como algo maléfico. A visão era associada ao "olho do mal”. Classen (1998), seguindo a mesma linha, demonstrou como a visão era associada à bruxaria na Idade Média na Europa.

$O$ conceito que o Ocidente tem da visão pode muito bem ser representada pela ideia que temos de fotografia. Em geral, nos bastamos com o que é retratado como se a foto fosse um retrato fiel da realidade, assim como acreditamos que o perfil estratigráfico que desenhamos em campo representa com exatidão absoluta as camadas sobrepostas de sedimento. Mas por exemplo ao observar uma série de fotos de animais um chefe de uma tribo da Tanzânia recorrentemente olhava na parte de trás das fotos e as considerava incompletas (Classen 1993). O chefe esperava na realidade que as fotos mostrassem o que ele conhecia dos animais fotografados, ou seja, que eles têm mais de um lado.

Distinções sensoriais podem também determinar diferenciações sociais. Por exemplo, as mulheres normalmente são vistas com maior aptidão ao tato, olfato e paladar, o que as torna inaptas ao trabalho intelectual associado à visão e à audição. Suas tarefas passam a ser limpar, cozinhar e cuidar da família (Classen 1998). Ao mesmo tempo, na Europa Moderna, primitivos eram aqueles associados aos sensos do olfato e do paladar, que eram considerados sensos menores, ligados ao desejo incontido. 
Modelos sensoriais em vez de privilegiar apenas um dos sensos, podem reunir também, de modo sinestésico, dois ou mais sentidos. Houston e Taube (2000) mostraram como a escrita atuava como meio de comunicação sinestésica entre os povos mesoamericanos antigos. Segundo os autores, a escrita entre os mesoamericanos não era apenas um registro passivo, mas um dispositivo pensado para ser falado através da linguagem vocalizada. Ainda segundo os autores, era possivel que os individuos olhassem as inscrições nos templos e monumentos e as decodificassem tanto de modo visual quanto de modo auditivo, literalmente escutando um orador proferir as palavras. Ler era como escutar alguém falando, da mesma maneira que parar de ler era como se estivessem interrompendo alguém falando.

Mudanças nos modelos sensoriais resultam na reorganização massiva do conhecimento e das práticas sociais. Dois bons exemplos são a criação do alfabeto e a revolução Neolítica.

Segundo Macluhan (1962), a invenção do alfabeto marcou o início da passagem dos modelos sensoriais auditivos para os modelos visuais, pois com a invenção da escrita a visão passou a ser no mundo ocidental o meio mais importante para a aquisição de conhecimento, processo este que se intensificou com a invenção da imprensa. Ong (1969) não só defendia esta ideia como argumentava que esta transformação nos modelos sensoriais teve profundos efeitos sobre a ordem social. Do ponto de vista cognitivo, segundo o autor, a importância da visão levou, por exemplo, ao compartilhamento das ciências e à dominância dos modos de pensamento objetivos e lineares. Classen (1997) nos dá uma série de exemplos da diminuição do simbolismo associado aos demais sentidos durante o império da visão.

Outro exemplo de como a mudança dos modelos sensoriais pode engendrar significativas mudanças na ordem social pode ser vista na interpretação que Tilley (2007) faz da Revolução Neolitica. Segundo o autor graças à mudança dos modelos sensoriais entre o final do Mesolítico e inicio do Neolítico, todas as ordens sociais, econômicas e culturais foram alteradas. Tal mudança teria sido decorrente da passagem do mundo florestado para os campos abertos. Para Tilley o mundo caçador coletor dos mesoliticos era o mundo das florestas, do ambiente fechado, do horizonte reduzido. Neste ambiente as zonas de maior visibilidade eram os topos de morro, os pântanos e as áreas limite da floresta. $\mathrm{O}$ intenso contato com estes ambientes fazia do cheiro, do tato e do som, sentidos mais importantes que a visão. $\mathrm{O}$ som do riacho, o cheiro de determinados tipos de plantas, o tato das texturas das árvores, tudo isso pode ter contribuido para a mobilidade destes grupos. Estes ambientes eram mais dinâmicos e os modelos sensoriais provavelmente trabalhavam sinestesicamente com a memória. Ao mesmo tempo, as possibilidades perceptivas da floresta poderiam ter tido importantes consequências simbólicas. Durante o periodo de transição para o Neolítico as florestas deram lugar a grandes áreas desmatadas. O desmatamento em grande escala permitia que a visão passasse a ser o senso dominante em termos de orientação espacial. Era possivel agora avistar o horizonte, controlar uma área de grande extensão de terra, admirar os topos de colina distantes etc.. Tilley acredita que o desmatamento produzido alterou significativamente os modelos sensoriais das comunidades Neoliticas, pois permitiu a criação de novas experiências perceptivas. Ele vê na instalação de diversos monumentos ao longo dos topos das colinas um exemplo desta mudança de perspectiva. A experiência da colina sem floresta foi substituida pela experiência dos monumentos em áreas altas e abertas.

\section{Uma nova maneira de vivenciar nossa Arqueologia}

Howes e Classen (2009) têm defendido a ideia de que a cultura material incorpora e expressa os modelos sensoriais de uma dada sociedade. Isto se daria não apenas na sua produção, através dos valores e habilidades sensoriais nela envolvidos, mas também nas qualidades sensoriais que os objetos apresentam depois de prontos, com suas formas, cores, estéticas, sons, texturas e no seu consumo, ou 
Mudando o coração, a mente e as calças. A Arqueologia Sensorial. Revista do Museu de Arqueologia e Etnologia, São Paulo, 20: 3-16, 2010

seja, nos significados que as pessoas atribuem à peça dentro do modelo sensorial vigente. Como afirmou Howes (2006a), da mesma maneira que os objetos suscitam sensibilidades eles são sensiveis aos modelos sensos-culturais de um grupo.

Mas, se modelos sensoriais são definidos e vivenciados culturalmente, seria possivel acessar os modelos sensoriais de outra cultura, seja ela do passado ou do presente? Seria possivel através de objetos, apreender os modelos experimentados por outros grupos? Creio que não totalmente, pois para compreender $\mathrm{o}$ modelo sensorial de outros grupos teríamos que desaprender nosso próprio modelo sensorial.

Mas a despeito deste impedimento, creio que o estudo dos aspectos sensoriais pode nos fornecer outras maneiras de ver os objetos do passado, ampliando nossa capacidade de interpretação. Ingold (2000) salienta que como parte da experiência perceptiva é aprendida, ação e participação com os materiais e paisagens são essenciais na tentativa de interpretálos. Sendo assim devemos descrever menos e vivenciar mais os objetos. O autor lembra que é a estrutura e a regularidade das atividades diárias que nos tornam próximos à experiência sensorial do lugar e dos objetos. Ainda segundo o autor, pesquisadores na sociedade moderna entendem muito pouco sobre a obtenção e preparo dos materiais tradicionais utilizados no passado principalmente no que se referem àqueles que têm pouco uso atualmente. Como ressalta Hurcombe (2007), muitos arqueólogos fazem interpretações sobre a cultura material sem nunca ter experimentado sua produção ou sua utilização. Segundo a autora isto afeta a construção sensorial do objeto e dificulta o entendimento de alguns aspectos da cultura material.

Dos cinco sensos aristotélicos, a visão é o sentido mais explorado tanto na prática quanto na interpretação arqueológica. No campo da arqueologia sensorial os aspectos visuais têm sido explorados, por exemplo, na significância das cores e dos perfis de visibilidade. Para Whitley et al. (1999), as qualidades sensoriais das matérias primas devem ser consideradas juntamente com suas caracteristicas tecnológicas. Em um dos seus exemplos o autor discute como o brilho do quartzo era um aspecto tangivel importante na escolha da matéria prima para algumas sociedades. Jones e MacGregor (2002) têm sugerido que o uso de rochas de diferentes litologias e colorações na construção das passagens das tumbas irlandesas do mesolitico criavam uma estrutura colorida que interferia no direcionamento e condução da luz natural para dentro dos monumentos. Em Clava Cairn, por exemplo, o monumento, criado com litologias diferentes, foi pensado para reagir diferentemente de acordo com os tipos de luz que incidiam nas paredes. Sendo assim durante o equinócio somente determinadas partes do monumento se iluminavam o mesmo acontecendo no solstício. Os autores concluem que a interrelação entre luz, cores e litologias especificas poderia sugerir performances especificas associadas com significações cosmológicas.

Em relação à audição uma série de arqueólogos tem explorado a ideia de soundscapes. $\mathrm{Na}$ tentativa de explorar novos sentidos para a paisagem, Scarre e Lawson (2006) trabalharam com a recriação dos sons cerimoniais da Idade do Bronze. De modo similar, Loose (2008) explorou os sons dos gritos e sinos em rituais antigos.

Embora menos estudado, o toque mostra um grande potencial para o entendimento de monumentos e artefatos. Macgregor (1999), por exemplo, trabalhou com as bolas de pedra neoliticas a partir da textura do material de confecção. Cummings (2002) analisou a textura das paredes dos monumentos neolíticos ingleses para determinar seu significado. Para a autora é essencial considerar não apenas o impacto das estruturas ou artefatos acabados, mas como isto poderia ter afetado os atos e gestos da própria confecção, afinal como aponta Lazzari (2005) seriam os objetos escolhidos por qualidades táteis especificas? Em alguns sítios o sentimento de assimetria foi alcançado através do uso de diferentes texturas e formas das pedras. Desde que a experiência é tanto subjetiva quanto culturalmente especifica, os construtores dos monumentos parecem ter 
deliberadamente incorporado muitos atributos assimétricos diferentes. A textura, a forma, cor, origem das pedras fornecem diferentes meios de estabelecer um sentimento de assimetria. Entrar nas pequenas câmaras deveria ter sido uma experiência desnorteante. Sem referências externas, o observador rapidamente perde seu senso de orientação em relação ao mundo externo. Sendo assim, o interior parece ter sido criado para possibilitar a identificação dos diferentes setores das câmaras.

Um dos sentidos mais dificeis de identificar no passado é o olfato. Mesmo assim sabemos que o olfato desempenha papel importante na maneira com que concebemos e interpretamos o mundo. Houston e Taube (2000) têm demonstrado a importância dos cheiros entre os mesoamericanos, principalmente no que se refere à comunicação com seres extra-sensoriais. Classen et al. (1994) têm demonstrado a associação entre o olfato e as experiências de memória e emoção. Segundo a autora, odor, memória e significado são elementos inter-relacionados. Segundo Hurcombe (2007), embora potes de cerâmica estejam mais associados com fogo e calor do ponto de vista sensorial, é possivel que em algumas situações o aroma por eles exalado tenha tido um simbolismo maior. Sendo assim, não seria estranho pensar que os potes enterrados nas sepulturas poderiam representar percepções mnemônicas para alimentação ou mesmo para os aromas e paladares associados com o pote.

Todos os exemplos acima servem para nos lembrar que existe mais nos objetos do que supõem nossas interpretações. Nosso modelo sensorial baseado na visão, falha em acessar a materialidade do passado por uma falha ontológica e epistemológica simples. Utilizamos um modelo sensorial diferente do que foi utilizado pelas culturas do passado. É neste sentido que Finnegan (2002) sugere que os objetos não devem ser lidos ou simplesmente interpretados, mas vivenciados. Os limites de nossa linguagem não são os limites de nosso mundo, como diria Howes (2005). Palavras e objetos, discursos e práticas materiais não são as mesmas coisas (Tilley 2002). Cacos cerâmicos não são imagens ou textos, são fragmentos de uma vivência, de uma percepção.

\section{De volta à Terra do Nunca}

Por que paramos de admirar o nascer do sol, as estrelas e a lua cheia? Por que paramos de dar formas às nuvens? Por que paramos de brincar na chuva? Por que paramos de nos emocionar a cada caco cerâmico encontrado em um sítio arqueológico? Para onde foi aquela euforia de cada nova descoberta?

Já é lugar comum atribuir ao ritmo da vida moderna nosso distanciamento com o mundo e com aquelas pequenas coisas que dão sentido a ela. Sair do lugar comum é na realidade fazer algo para mudar essa realidade, para acabar com essa morte em vida. Diariamente nos esquecemos de tudo aquilo que realmente deveria ser mais importante. Nos esquecemos de parar para perceber o mundo a nossa volta.

$\mathrm{Na}$ arqueologia creio que não é diferente. O distanciamento que temos dos objetos com que trabalhamos, das paisagens e sítios que escavamos, se deve em primeiro lugar ao trato cotidiano que temos com este universo. Vemos tantos cacos, tantas sondagens, tantos sítios que estes passam a ser lugar comum. Em segundo lugar, se deve ao fato de que nossos modelos sensoriais, baseados na preponderância da visão, determinam um distanciamento dos objetos com que lidamos. Segundo Howes (2005), no Ocidente concebemos os sensos como recipientes passivos de dados, como faculdades naturais. Nossa ordem sensorial nos parece tão natural que temos dificuldade em concebê-la como produto cultural. Somente quando examinamos os diferentes modelos sensoriais praticados por outras sosiedades é que a construção cultural da percepção se torna clara. Mas como abordamos o estudo sobre outras culturas a apartir de nosso próprio modelo sensorial, o conhecimento dos simbolismos associados com os sentidos permanesce reduzido. Gosden (2001) tem alertado que para apreciarmos o mundo sensorial dos outros deveriamos desaprender nossa própria educação sensorial, com sua predisposição para o 
Mudando o coração, a mente e as calças. A Arqueologia Sensorial. Revista do Museu de Arqueologia e Etnologia, São Paulo, 20: 3-16, 2010.

visual. Estas abordagens talvez não produzam respostas definitivas sobre como monumentos e artefatos eram construidos, confeccionados, concebidos e utilizados, mas nos encoraja a reconhecer, a discutir a complexa relação que as pessoas tinham com seu meio. Isso significa atender aos significados codificados em todos os sentidos. Essa atenção pode descobrir uma riqueza de simbolismo sensorial anteriormente negligenciada pelos estudiosos e pode revelar hierarquias de valores sensoriais diferentes da ordem visual que dominou o Ocidente (Classen 1997).

Sem pretender ser a resposta para todas as aflições da Arqueologia, as abordagens fenomenológicas têm auxiliado na desconstrução das abordagens dualistas, produto do racionalismo cartesiano. Tal desconstrução facilita a reconsideração da natureza da materialidade e da relação entre as pessoas e o mundo material. $\mathrm{O}$ mundo material não é inanimado, ele nos afeta e nos torna quem somos. Sendo assim, nossa relação com o mundo material, com os machados, lesmas, enterramentos, passa a ser considerada como um diálogo em que ambos, arqueó- logo e artefatos, são criados e transformados (Jones 2002).

A mecanização de nossas atividades tirou o sentido mais profundo do que fazemos e tornou a ciência arqueológica enfadonha, repetitiva e estéril. Quem depois de anos de carreira ainda tem aquela emoção pueril ao desenterrar um objeto ou ao terminar o nivel cinco da sondagem? Um caco é só mais um caco, uma sondagem é apenas mais uma sondagem. Mas cada caco é único, cada fragmento de lasca é único. Único, pois representa a vida de alguém que transformou a matéria em artefato; único nas experiências e sensações que estão por detrás de cada fragmento.

Ao final me despeço de vocês esperando nossa próxima aventura. Deixo apenas um recado: lembre-se, podemos ter perdido a nossa inocência, mas não perderemos nossa fantasia. Esses cacos cerâmicos que encontramos todos os dias não são apenas cacos cerâmicos, eles são mágicos. Como nos aconselhou o homem no rio, faça as perguntas certas e um mundo maravilhoso pode se abrir para você. A vida é uma só, aproveite-a bem e faça as perguntas que você deve fazer!

PELLINI, J.R. Changing your heart, your mind and your paints. The Sensorial Archaeology. Revista do Museu de Arqueologia e Etnologia, São Paulo, 20: 3-16, 2010.

Abstract: How has pointed Classen (1993, 1997) and Howes (1991, 2006), ethnographic, historical and anthropological studies have shown that sensory perception is a cultural construct, or, the meanings that individuals attribute to the sensory aspects are based on sensory models adopted socially. Thus each culture sees the senses differently establishing its own sensory hierarchies (Howes 2006). In this sense, an understanding of the sensory world is not only a physiological aspect, but it is culturally determined. The groups recognize the human sensory apparatus in accordance with its own context, creating and changing senses, creating and altering sensory hierarchies. We learn to see, hear, feel. We learn to observe and not observe. In this sense the Sensory Archaeology seeks to understand the human experience through an understanding of how is the relationship between individuals and the material world, assuming that is the same way that the objects they raise sensitivities are sensitive to the sensory models and cultural senses of a group.

Keywords: Sensorial Archaeology - Perception - Phenomenology - Materiality. 


\section{Referências bibliográficas}

BASSO, E.

1985 Musical view of the universe: Kalapalo mith and ritual performances. Philadelphia: University of Pennsylvania Press.

BERGSON, H.

1990 Matéria e memória. Trad. Paulo Neves. São Paulo: Martins Fontes.

BORGES, D

1986 Rio Araguaia. Corpo e Alma. São Paulo: IBRASA.

CHAUÍ, M.

2000 Convite a filosofia. São Paulo: Ática.

CLASSEN, C.

1993 Worlds of sense. New York: Routledge.

1997 Foundations for an anthropology of the senses. International Social Science Journal, 153: 401-20

1998 The color of angels: cosmology, gender and the aesthetic imagination. London: Routledge.

CLASSEN, C.; HOWES, D; SYNNOT, A.

1994 Aroma. The cultural history of smell. London: Routledge.

COBRA, R.

2005 Fenomenologia. Filotemas In: www.cobra.pages.nom.br

CRARY, L.

1990 Techniques of the observer: on vision and modernity in the nineteenth century. Cambridge: MIT Press.

CUMMINGS, $\mathrm{V}$.

2002 Experiencing texture and transformation in the British Neolithic. Oxford Journal of Archaeology, 21 (3): 249-261.

DENNETT, D.

1991 Quining qualia. In: Marcel, A.; Bisiach, E. (Eds.) Consciousness in modern science. Oxford, Oxford University Press: 42-77.

DUBORD, G.

1995 The society of the spectacle. New York: Zone Books.

DUNDES, A.

1981 The evil eye: a folklore casebook. New York: Garland.

FINNEGAN, R.

2002 Communicating: the multiple modes of human interconnection. London: Routledge.

GALLAGHER, S.; ZAHAVI, D.

2008 The phenomenological mind. An introduction to philosophy of mind and cognitive science. London: Routledge.

GEBHART-SAYER, A

1985 The geometric designs of the Shipibo-
Conibo in ritual context. Journal of Latin American Lore, 11 (2): 143-75.

GEURTS, K.

2002 Culture and the senses: bodily ways of knowing in an African community. Berkeley: University of California Press.

GOSDEN, C.

2001 Making sense: archaeology and aesthetics. World Archaeology, 33 (2): 163-167.

HOUSTON, S.; TAUBE, K.

2000 An archaeology of the senses: perception and cultural expression in ancient Mesoamerica. Cambridge Archaeological Journal, 10 (2): 261-94.

HOWES, D.

1991 The varieties of sensory experience: A sourcebook in the anthropology of the senses. Toronto: University of Toronto Press..

2005 Sensescapes: embodiment, culture and environment. In: Classen, C. (Ed.) The Book of Touch. Oxford: Berg.

2006 Charting the sensorial revolution. Senses and Society, 1(1): 113-128.

2006a Cross-talk between the senses. Senses and Society, 1 (3): 381-390.

HOWES, D; CLASSEN, C.

2009 Doing sensory anthropology. www.sensorystudies.org/?page $i d=355$

HURCOMBE, L.

2007 Archaeological artefacts as material culture. London: Routledge.

HUSSERL, E.

1962 Ideas: general introduction to pure phenomeno logy. London: Collier MacMillan Publishers.

1970 The crisis of European sciences and transcendental phenomenology. An introduction to phenomenology. Trans. D. Carr. Evanston: Northwestern University Press.

INGOLD, T.

2000 The perception of the environment. London: Routledge.

JACOBS, M.

2006 The production of mindscapes. A comprehensive theory of landscape experience. Dissertation Wagenigen Univertsity.

JARVILEHTO, T.

1999 The theory of the organism-entorn system III: role of efferent influences on receptors in the formation of knowledge. Integrative Physiological and Behavior Science, 34 (2): 90-110. 
JONES, A.; MACGREGOR, G.

2002 Colouring the past. The significance of colour in archaeological research. Oxford: Berg.

JONES, A

2002 Archaeological theory and scientific practice. Cambridge: Cambridge University Press.

KASCHAK, M.; GLENBERG, A

2000 Constructing meaning: the role of affordances and grammatical consturctions in sentence comprehension. Journal of Memory and Langauge, 43: 508-29.

KENSINGER, K.

1995 How real people ought to live: The cashinahua of eastern Peru. Prospect Heights, IL: Waveland Press.

LAZZARI, M.

2005 The texture of things, objects, people and landscape in northwestern Argentina (First Millennium AD). In: Meskell, L. (Ed.) Archaeologies of Materiality. Oxford, Blackwell :126-161.

LOOSE, R.

2008 Tse'Biinaholts'a Yalti (curved rock that speaks). Time and Mind 1(1): 31-50.

MACGREGOR, G.

1999 Making sense of the past: a sensory analysis of carved stone balls. World Archaeology, 31: 258-71.

MACLUHAN, M

1962 The Gutenberg Galaxy: The making of typogra phic man. Texas: University of Texas Press.

MALONEY, C.

1976 The evil eye. New York: Columbia University Press.

MATURANA, H.; VARELA, F.

1995 A árvore do conhecimento: as bases biológicas do entendimento humano. Trad. Jonas Pereira dos Santos. Campinas: editorial Psy.

MERLEAU-PONTY, M.

1962 Phenomenology of perception. London: Routledge.

NÓBREGA, T.

2000 Núcleos interpretativos para uma teoria da corporeidade: o corpo em movimento.
In: www.anped.org.br/reunioes/23/textos/ 1714t.PDF.

2008 Corpo, percepção e movimento em MerleauPonty. Estudos de Psicologia, 13 (2): 141-148.

NOE, A.

2004 Action in perception. Cambridge: MIT Press. ONG, W.

1969 World as review and world as event. American Anthropologist, 71: 634-647.

REID, T.

1970 An inquiry into the human mind. Chicago: University of Chicago Press.

RITCHIE, I.

1991 Fusion of the faculties: a study of the language of the senses in Hausaland. In: Howes, D. (Ed.) The Varieties of Sensor Experience. Toronto: University of Toronto Press.

RODAWAY, P.

1994 Sensuous geographies: body, sense, and place. London: Routledge.

SCARRE, C.; LAWSON., G.

2006 Archaeoacoustics. Cambridge: MacDonald Institute for Archaeological Research.

SEEGER, A.

1975 The meaning of body ornaments. Ethnology, 14 (3): 211-24.

TILLEY, C.

2002 Metaphor, materiality and interpretation. In: Buchli, V. (Ed.) The MaterialCulture Reader. Oxford, Berg: 23-56.

2007 The neolithic sensory revolution: monumentality and experience of landscape. Proccedings of Brithish Academy, 144: 329-345.

VAN EDE, Y.

2009 Sensuous anthropology: sense and sensibility and the rehabilitation of skill. Anthropological Notebooks, 15(2): 61-75.

WHITLEY, D.; DORN, R.; SIMON, J.; RECHTMAN, R.; WHITLEY, T.

1999 Sally's Rockshelter and the archaeology of the vision quest. Cambridge Archaeological Journal, 9 (2): 221-46. 